\title{
Factors Affecting Lecithin Synthesis by Fetal Lung Cells in Culture
}

\author{
BARRY T. SMITH(42) AND JOHN S. TORDAY
}

The McGill University-Montreal Children's Hospital, Research Institute, Montreal, Quebec, Canada

\section{Extract}

In monolayer cultures prepared from fetal rabbit lungs of 28 days gestation, cortisol, dexamethasone, and L-thyroxine enhanced choline incorporation into lecithin, but had no effect on the methylation pathway. Heroin did not affect the incorporation of either precursor. Hyperoxia and metabolic acidosis decreased lecithin biosynthesis from both precursors. Over $90 \%$ of the lecithin was recovered from the cells after 6 hr of incubation. Release of newly synthesized lecithin was low until 10-12 $\mathrm{hr}$, then rapidly increased, reaching $40-50 \%$ after $24 \mathrm{hr}$. The proportion of the lecithin which was disaturated was not different between the intracellular and extracellular compartments. None of the experimental variables altered the degree of saturation. Short term mixed cell cultures provide a useful approach to the study of mammalian lung development.

\section{Speculation}

The study of mixed populations of fetal lung cells under conditions of short term monolayer culture provides a simple means of studying the influence of various agents and culture conditions on the biosynthesis of disaturated lecithin, a biochemical index of pulmonary maturation. This approach allows the study of viable, functioning cells under conditions which can be precisely controlled and which can be manipulated in a variety of ways. Inductive effects, which may require a lag time of hours or days, can be demonstrated readily.

The maturation of the fetal lung is linked to the formation of a surface-active alveolar lining layer, generally referred to as the pulmonary surfactant, which contains a high proportion of dipalmityl lecithin (4). This surface-active phospholipid is thought to be produced in alveolar type II cells by two possible pathways (11): (1) the incorporation of choline into an $\alpha, \beta$-diglyceride, and (2) the introduction of three methyl groups, derived from methionine, into phosphatidyl ethanolamine. Much interest has been shown in the enhancement of surfactant biosynthesis by pharmacologic means (2) and a number of agents, including corticosteroids $(7,13-15,23)$, thyroxine $(20,25)$, and heroin $(22)$ have been reported to be active in this respect. We previously described the maintenance in culture of mixed cell populations of fetal rabbit lung in which active incorporation of $\left({ }^{14} \mathrm{C}\right)$ palmitate into lecithin was demonstrated and which, in cultures derived from late gestation fetuses, were responsive to glucocorticoids in terms of increased incorporation of palmitate into lecithin (21). In the present study, we examine the effects of various agents and culture conditions on the pathways of lecithin biosynthesis in a similar cell preparation.

\section{MATERIALS AND METHODS}

Ham's F-10 tissue culture medium (26) was supplemented with $10 \%$ fetal calf serum (27), penicillin (100 U/ml) (28), gentamicin $(10 \mu \mathrm{g} / \mathrm{ml})(29)$, and amphotericin B $(5 \mu \mathrm{g} / \mathrm{ml})$ (30). This preparation will subsequently be referred to as "control medium." Experimental media were prepared by addition to the control medium of cortisol (31) at a concentration of $5.5 \times 10^{-6} \mathrm{M}$ as described previously (21), dexamethasone $\left(5.5 \times 10^{-8} \mathrm{M}\right)(32)$, thyroxine $\left(10^{-6} \mathrm{M}\right)(33)$, or heroin $\left(10^{-8} \mathrm{M}\right)(34)$. In addition, metabolic acidosis was simulated by titration of the control medium ( $\mathrm{pH} 7.40$ ) to a $\mathrm{pH}$ of 6.90 with $1 \mathrm{~N}$ hydrochloric acid and hyperoxia by bubbling $95 \% \quad \mathrm{O}_{2} / 5 \% \mathrm{CO}_{2}$ into the control medium until a $\mathrm{P}_{\mathrm{O}_{2}}$ of 350 Torr was achieved.

This preparation of the cell cultures has been described in detail previously (21). It involves the exposure of lungs obtained from fetal rabbits of known time of gestation to $0.25 \%$ trypsin (35) in calcium-free Krebs-Ringer bicarbonate buffer. In the present experiments, the fetal lungs obtained from three litters of 28 days gestation were pooled, minced, and stirred at $37^{\circ}$ in this enzyme mixture until all tissue fragments were dispersed. The tissue digest was filtered through four layers of sterile cotton gauze and centrifuged for $10 \mathrm{~min}$ at $200 \times \mathrm{g}$. After two washes of the cell pellet, the cells were resuspended in control medium and aliquots containing $2 \times 10^{6}$ cells were transferred into plastic culture flasks with a surface area of $25 \mathrm{~cm}^{2}$ (36) which contained either control media or media with cortisol, dexamethasone, thyroxine, or heroin. Five replicate flasks were prepared for each variable. The flasks were flushed with $5 \% \mathrm{CO}_{2}$, tightly stoppered, and maintained at $37^{\circ}$. Media were changed $24 \mathrm{hr}$ after implantation and every $48 \mathrm{hr}$ thereafter. In the case of cells exposed to hyperoxia or acidosis, the cells were implanted in control medium and the appropriate experimental media were added only after $72 \mathrm{hr}$ in order to allow the cultures to become established under optimal conditions.

Six days after implantation, when all cultures had reached confluence, the media were replaced with $5 \mathrm{ml}$ of serum-free F-10 culture medium containing equimolar amounts (1.5 nmol $)$ of choline chloride, $\left({ }^{3} \mathrm{H}\right)$ methyl $\left(2 \times 10^{6} \mathrm{dpm}\right.$, sp act $2.34 \mathrm{Ci} / \mathrm{mmol})(37)$, and $S$-adenosyl-L-methionine, $\left({ }^{14} \mathrm{C}\right)$ methyl $\left(2 \times 10^{5} \mathrm{dpm}\right.$, sp act $\left.58 \mathrm{mCi} / \mathrm{mmol}\right)$ (37). After incubation for $6 \mathrm{hr}$, the media were decanted and the cells rinsed with $1 \mathrm{ml}$ isotonic saline solution. The rinses were added to the media. The cells were detached from the surface of the flasks with the aid of a rubber policeman, resuspended in saline solution, and disrupted by sonication. The cells and media were processed separately for the chromatographic isolation of radiolabeled lecithin, as described previously (21). Aliquots of the recovered lecithins were counted for their content of each isotope in a Packard Tri Carb liquid scintillation spectrometer, model 4322, with an efficiency for 
${ }^{14} \mathrm{C}$ and ${ }^{3} \mathrm{H}$ of $59 \%$ and $17 \%$, respectively. Results were calculated from the amounts of either ${ }^{3} \mathrm{H}$ or ${ }^{14} \mathrm{C}$ incorporated into lecithin, and in either case are expressed as picomoles of lecithin formed from these precursors (38). The mean and standard deviation were calculated for each group of observations and differences were compared using Student's $t$ test.

After counting of radioactivity, the remaining lecithin fractions were pooled within the various experimental groups and the percentage of disaturated lecithin determined for each by thin layer chromatography of the mercuric acetate adducts $(16,21)$.

In a separate group of cultures, the time course of lecithin biosynthesis and release into the culture medium was studied over a period of $24 \mathrm{hr}$, after the addition of serum-free medium containing $\left({ }^{3} \mathrm{H}\right)$ choline in the same concentration as quoted above.

\section{RESULTS}

The amounts of lecithin, recovered in the cells or from the media, formed from either $\left({ }^{3} \mathrm{H}\right)$ choline or $\left({ }^{14} \mathrm{C}\right)$ methionine after $6 \mathrm{hr}$ of incubation, are shown in Table 1 . Cortisol, dexamethasone, and L-thyroxine enhanced choline incorporation but had no effect on the methylation pathway. Cortisol enhanced total (as measured in the cells plus the media) choline incorporation from $14.9 \pm 3.1 \mathrm{pmol}$ lecithin/flask to $34.7 \pm 10.6$ (T 3.439, $P<0.01$ ), dexamethasone from $14.9 \pm$ 3.1 to $37.4 \pm 7.9$ (T $5.885, P<0.001$ ), and L-thyroxine from $14.9 \pm 3.1$ to $31.3 \pm 9.2$ (T $3.755, P<0.01$ ). Heroin had no effect on the incorporation of either precursor.

Hyperoxia and metabolic acidosis decreased lecithin biosynthesis from both precursors to a similar extent; under conditions of acidosis, choline incorporation was reduced to $6.9 \pm 3.0$ (T 4.080, $P<0.01$ ) and methylation to $0.5 \pm 0.1$ ( $\mathrm{F}$ $4.620, P<0.01)$; in the case of hyperoxia, choline incorporation was reduced to $9.4 \pm 1.8$ (T $3.323, P<0.01$ ) and methylation to $0.6 \pm 0.2$ (T $4.223, P<0.01$ ).

In all cases, over $90 \%$ of the lecithin was recovered from the cells. However, when the incubation was continued for a more prolonged time period (Fig. 1), it was found that, although synthesis was maximal in the first $12-18 \mathrm{hr}$, the release of newly synthesized lecithin (as monitored by the release into the media of labeled lecithin) was low until 10-12 hr, then rapidly increased, reaching $40-50 \%$ after $24 \mathrm{hr}$.

The proportion of the recovered lecithin which was disaturated ranged from 50 to $61 \%$ (mean 54\%) (Table 2) and there was no difference between the intracellular and extracellular compartments. None of the experimental variables altered the degree of saturation.

\section{DISCUSSION}

The enhancing effect of glucocorticoids and thyroxine on the synthesis of disaturated lecithin as reported here is in general agreement with results of studies carried out in a variety of species, which have established that these hormones can induce accelerated maturation of the fetal lung $(7,13-15$, $20,23,25)$. Heroin, however, had no effect on lecithin biosynthesis in the fetal lung cell cultures, although it enhances pulmonary maturation in the fetal rabbit in vivo (22). This suggests that heroin acts on the lung by mechanisms different than those involved in the action of the above hormones.

Exposure of the cells to acidosis depressed the incorporation of both precursors into lecithin, although it has been suggested that in vivo the methylation pathway of lecithin synthesis is more sensitive to acidosis (12). However, it might be that less drastic changes in $\mathrm{pH}$ would have had a different effect.

The toxic effect of oxygen on both adult and neonatal lung resulting in unstable pressure-volume relations is well known, although the mechanism of this toxicity remains unclear (5). The present study suggests that it could be linked, at least in part, to a depressor effect on lecithin synthesis. In this context, it is of interest that hyperoxia has recently been shown to cause a loss of mitochondrial granules from type II cells (17). However, the possibility remains that in our experimental conditions the effect of oxygen was a nonspecific one mediated through the release of lysosomal enzymes (19).

The degree of saturation of the lecithins was remarkably constant, varying from 50 to $61 \%$, and no differences were observed between the intracellular and extracellular pools. This suggests that the mechanism of release, as it operates in this system, does not differentiate between saturated and unsaturated lecithins. Similarly, while cortisol, dexamethasone, and thyroxine enhanced lecithin synthesis via choline incorporation, they did not affect the proportion which was

Table 2. Percentage of recovered lecithins found to be disaturated

\begin{tabular}{lcc}
\hline & \multicolumn{2}{c}{ Disaturated lecithin, \% } \\
\cline { 2 - 3 } Culture conditions $^{2}$ & Cells & Media \\
\hline Control & 50 & 61 \\
Cortisol & 52 & 55 \\
Dexamethasone & 54 & 53 \\
L-Thyroxine & 59 & 53 \\
Heroin & 54 & 55 \\
Hyperoxia & 51 & 50 \\
Acidosis & 52 & 52 \\
\hline
\end{tabular}

\footnotetext{
${ }^{1}$ As determined from the pooled lecithin fractions.

${ }^{2}$ For the concentrations of the experimental variables see Materials
} and Methods. Table 1. Picomoles of lecithin $( \pm S D)$ formed from incorporation of $\left({ }^{3} \mathrm{H}\right)$ choline and $\left({ }^{14} \mathrm{C}\right)$ methionine and recovered in cellular and media fractions ${ }^{1}$

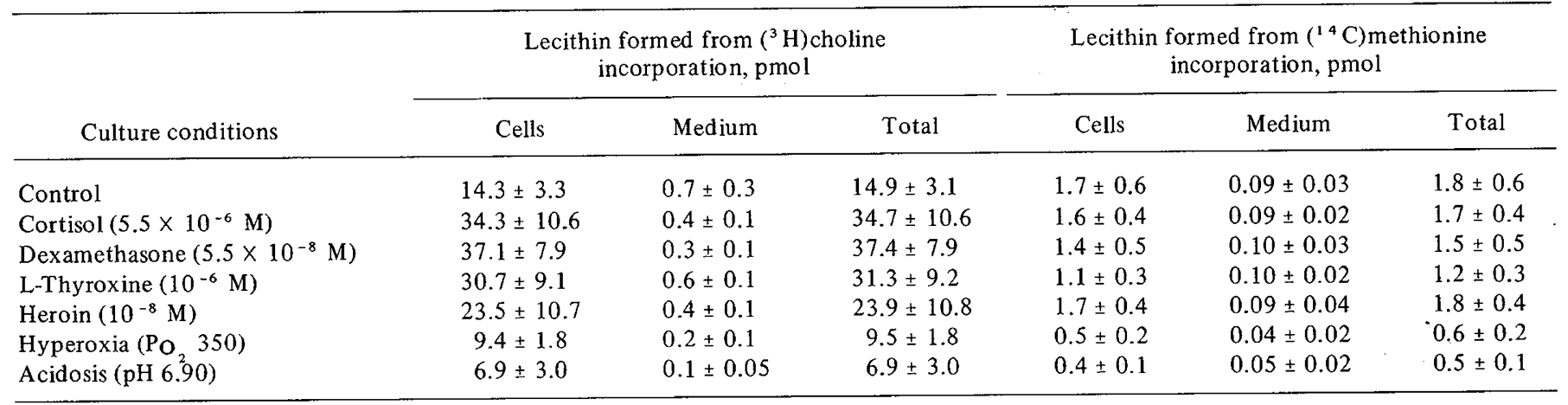

${ }^{1}$ After $6 \mathrm{hr}$ of incubation with cells prepared from 28 day gestation fetal rabbit lungs and maintained in culture for 6 days. 
disaturated. This could indicate that the action of these hormones on the biosynthetic process takes place beyond the introduction of the acyl groups, an assumption which is probably correct in the case of glucocorticoids inasmuch as they have been shown to increase the content and/or activity of lung choline phosphotransferase (8).

It is believed that the pulmonary type $I I$ cell synthesizes and stores surfactant in intracellular lamellar inclusions. This material is later secreted into the alveolar space where, at the alveolar-air interface, its surface active properties enhance lung stability (18). Interestingly, the time course of lecithin synthesis and release (Fig. 1) observed in culture appears to follow a similar sequence of events. Cultures pretreated with cortisol for 6 days showed enhanced incorporation of the precursor into lecithin in the intracellular compartment and, subsequently, increased amounts were released into the media.

Thus, despite the mixed, and essentially undefined, cell types present, these cultures respond in a way which is both biochemically reproducible and which, by and large, is in remarkable agreement with current concepts of fetal pulmonary maturation and lecithin synthesis. Certainly, it cannot be stated whether the effects noted are direct effects on the surfactant-synthesizing cell, the alveolar type II cell. Hormone induction of enzyme activity is now generally recognized, and, in the case of steroids, it is believed that such effects are preceeded by binding of the steroid to specific cytoplasmic receptors. The steroid-receptor complex then migrates to the nucleus where it is bound and affects the genome in a manner as yet undefined (24). Specific cytoplasmic binding proteins and nuclear receptor sites have been described in both rabbit and human fetal lung $(3,9,10)$. It is therefore possible that the enhancement of choline incorporation into lecithin observed in cultures exposed to these steroids is induced in a similar manner. Certainly our results, together with the observations of Farrell and Zachman (8), which show increased choline phosphotransferase activity in rabbit fetal lung in response to corticosteroids, favor the view that enzyme induction is involved. However, induction of enzymes in the alveolar type II cells need not be a direct effect of the hormone on these cells, but could involve effects on other cell types leading to the formation of intercellular mediators which would act upon the target type II cell. Alescio and Dani (1) have shown in embryonic mouse lung that glucocorticoidinduced glycogen deposition in epithelial cells is dependent upon the presence of homologous mesenchymal elements. It cannot be entirely ruled out that these hormones possess the ability to stimulate differential growth of various cell types,

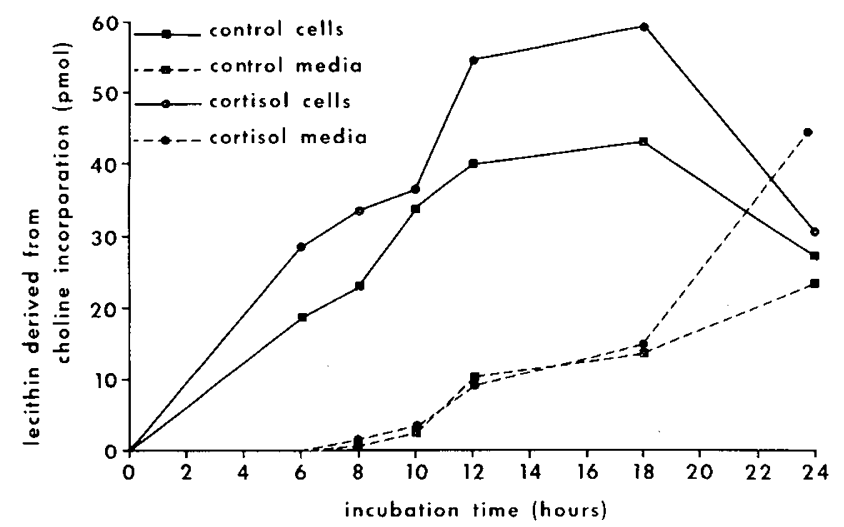

Fig. 1. The effect of time of incubation on the incorporation of $\left({ }^{3} \mathrm{H}\right)$ choline in to lecithin recovered in the cells $(-)$ and media $(---)$ of monolayer cultures of cells prepared from 28 day gestation rabbit fetal lungs and maintained in vitro for 6 days. The increased activity of cortisol pretreated cultures $(\bullet)$ in relation to control cultures $(\boldsymbol{\bullet})$ can be seen. Abscissa: length of incubation (hours); ordinate: picomoles of lecithin recovered per flask. resulting in a larger population of type II cells after a period of in vitro growth. Indeed, we reported previously that cortisol favored epithelial growth, as opposed to fibroblastic proliferation, in this system (21).

Although the precise answers to these questions must await the development of techniques to isolate and maintain pure populations of the various lung cell types in vitro, short term mixed cell cultures such as those used here appear to provide a useful approach to the study of mammalian lung development, especially if the results obtained are carefully analyzed in light of observations made in more complex systems.

\section{SUMMARY}

We have used short term mixed monolayer cell cultures prepared from fetal rabbit lungs at 28 days gestation to examine the effects of various agents and culture conditions on lecithin biosynthesis. Cortisol, dexamethasone, and L-thyroxine enhance lecithin synthesis solely by their effects on choline incorporation. Heroin was inactive. Acidosis and hyperoxia reduce lecithin synthesis, depressing both biosynthetic pathways to a similar extent. The time course of lecithin synthesis and release indicates that there is a lag between choline incorporation into lecithin and release of this phospholipid into the medium. Cell culture techniques can provide a useful approach to the study of developmental processes.

\section{REFERENCES AND NOTES}

1. Alescio, T., and Dani, A. M.: Hydrocortisone-increased glycogen deposition and its dependence on tissue interactions in mouse embryonic lung developing in vitro. J. Embryol. Exp. Morphol., 27: 155 (1972).

2. Avery, M. E.: Pharmacological approaches to the acceleration of fetal lung maturation. Brit. Med. Bull., in press.

3. Ballard, P. L., and Ballard, R. A.: Glucocorticoid receptors and the role of glucocorticoids in fetal lung development. Proc. Nat. Acad. Sci. U. S. A., 69: 2668 (1972).

4. Buckingham, S., and Avery, M. E.: Time of appearance of lung surfactant in the foetal mouse. Nature, 193: 688 (1962).

5. Clark, J. M., and Lambertsen, C. J.: Pulmonary oxygen toxicity: A review. Pharmacol. Rev., 23: 37 (1971).

6. Clements, J. A.: Composition and properties of pulmonary surfactant. In: C. A. Villee, D. B. Villee, and J. Zuckerman: Respiratory Distress Syndrome, p. 78 (Academic Press, New York, 1973).

7. deLemos, R., Shermeta, D. W., Knelson, J. H., Kotas, R., and Avery, M. E.: Acceleration of appearance of pulmonary surfactant in the fetal lamb by administration of corticosteroids. Amer. Rev. Resp. Dis., 102: 459 (1970).

8. Farrell, P., and Zachman, R.: Induction of choline phosphotransferase and lecithin synthesis in the fetal lung by corticosteroids. Science, 179: 297 (1973).

9. Giannopoulos, G.: Glucocorticoid receptors in lung. I. Specific binding of glucocorticoids to cytoplasmic components of rabbit fetal lung. J. Biol. Chem., 215: 3876 (1973).

10. Giannopoulos, G., Mulay, S., and Solomon, S.: Glucocorticoid receptors in lung. II. Specific binding of glucocorticoids to nuclear components of rabbit fetal lung. J. Biol. Chem., 215: 5016 (1973).

11. Gluck, L., Landowne, R. A., and Kulovich, M. V.: Biochemical development of surface activity in mammalian lung. III. Structural changes in lung lecithin during development of the rabbit fetus and newborn. Pediat. Res., 4: 352 (1970).

12. Gluck, L., Kulovich, M. V., Eidelman, A. I., Cordero, L., and Khazin, A. F.: Biochemical development of surface activity in mammalian lung. IV. Pulmonary lecithin synthesis in the human fetus and newborn and etiology of the respiratory distress syndrome. Pediat. Res., 6: 81 (1972).

13. Kotas, R., and Avery, M. E.: Accelerated appearance of pulmonary surfactant in the fetal rabbit. J. Appl. Physiol., 30:358 (1971).

14. Liggins, G. C.: Premature delivery of foetal lambs infused with glucocorticoids. J. Endocrinol., 45: 515 (1969).

15. Liggins, G. C., and Howie, R.: A controlled trial of antepartum glucocorticoid treatment for prevention of the respiratory distress syndrome in premature infants. Pediatrics, 50: 515 (1972).

16. Mangold, H.: Thin-layer chromatography of lipids. J. Amer. Oil Chem. Soc., 38: 708 (1961).

17. Massaro, G. D., and Massaro, D.: Pulmonary granular pneumocytes. Loss of mitochondrial granules during hyperoxia. J. Cell Biol., 59: 246 (1973). 
18. Morgan, T. E., and Morgan, B. C.: Surfactant synthesis, storage and release by alveolar cells. In: C. A. Villee, D. B. Villee, and J. Zuckerman: Respiratory Distress Syndrome, p. 117 (Academic Press, New York, 1973).

19. Pathak, S., and Fisk, A.: Histological and ultrastructural changes in the pars distalis of the rabbit pituitary in organ culture. $J$. Endocrinol., 60: 155 (1974)

20. Redding, R. A., Douglas, W. H. J., Wunschell, K. R., and Stein, M.: Influence of thyroid hormone upon lung ultrastructure and surfactant production. Fed. Proc., 30: 619a (1971).

21. Smith, B. T., Torday, J. S., and Giroud, C. J. P.: Evidence for different gestation dependent effects of cortisol on cultured feta lung cells. J. Clin. Invest., in press.

22. Taeusch, H. W. Jr, Carson, S., Wang N. S., and Avery, M. E.: Heroin induction of lung maturation and growth retardation in fetal rabbits. J. Pediat., 82: 869 (1973).

23. Taeusch, H. W., Jr., Heitner, M., and Avery, M. E.: Accelerated lung maturation and increased survival in premature rabbits treated with hydrocortisone. Amer. Rev. Resp. Dis., 105: 971 (1972).

24. Thomas, P. J.: Steroid hormones and their receptors. J. Endocrinol. 57: 333 (1973)

25. Wu, B., Kikkawa, Y., Orzalesi, M., Motoyama, E., Kaibara, M., Zigas, C., and Cook, C. D.: The effects of thyroxine on the maturation of fetal rabbit lungs. Biol. Neonat., 22: 161 (1973). 26. Microbiological Associates, Bethesda, Md.

27. Flow Laboratories, Rockville, Md.

28. Therapex, Montreal, Canada.

29. Roussel, Montreal, Canada.

Copyright () 1974 International Pediatric Research Foundation, Inc.
30. E. R. Squibb \& Sons, Montreal, Canada.

31. Steraloids, Pawling, N. Y.

32. Merck Sharp and Dohme (Canada), Kirkland, Quebec, Canada.

33. Sodium-L-thyroxine $5 \mathrm{H}_{2} \mathrm{O}$, Sigma, St. Louis, Mo.

34. The criteria of purity of this substance have been given previously (22).

35. Difco, Detroit, Mich

36. Falcon Plastics, Oxnard, Calif.

37. New England Nuclear, Boston, Mass.

38. The amount of lecithin derived from each pathway was calculated by the formula: $L=\mathrm{dpm} /(\mathrm{sp}$ act $\times \mathrm{M})$ where: $L=$ lecithin produced (picomoles); $\mathrm{dpm}=$ disintegrations per minute of either produced (picomoles); $\mathrm{dpm}=$ disintegrations per minute of either label $\left({ }^{3} \mathrm{H}\right.$ or $\left.{ }^{14} \mathrm{C}\right)$ recovered in the lecithin fraction; sp act $=$ the specific activity (disintegrations per minute per picomole) of each precursor (i.e., 1,333 for $\left({ }^{3} \mathrm{H}\right)$ choline and 133 for $\left({ }^{14} \mathrm{C}\right)$ methionine); $M=$ the number of moles of precursor incorp

39. We gratefully acknowledge the continuing support and advice of Drs. C. J. P. Giroud and M. E. Avery.

40. Supported by a grant to Dr. C. J. P. Giroud, from the Medical Research Council of Canada.

41. This was publication no. 425, McGill University-Montreal Children's Hospital Research Institute; presented in part at the 17 th Aspen Lung Confernece, Aspen, Colorado, June 12, 1974.

42. Requests for reprints should be addressed to: Dr. B. T. Smith, M.D., Rm. 1228, The Montreal Children's Hospital, 2300 Tupper St., Montreal, Quebec H3H 1P3, Canada.

43. Accepted for publication June 24, 1974.

Printed in U.S.A. 